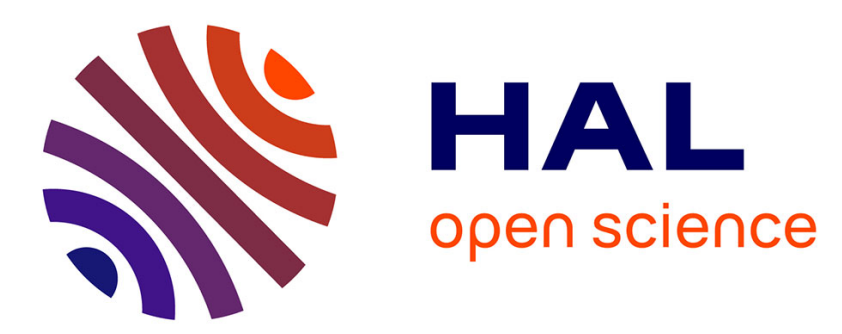

\title{
Fully three-dimensional direct numerical simulation of a plunging breaker
}

Pierre Lubin, Stéphane Vincent, Jean Paul Caltagirone, Stéphane Abadie

\section{To cite this version:}

Pierre Lubin, Stéphane Vincent, Jean Paul Caltagirone, Stéphane Abadie. Fully three-dimensional direct numerical simulation of a plunging breaker. Comptes Rendus Mécanique, 2003, 331 (7), pp.495501. 10.1016/S1631-0721(03)00108-6 . hal-00294098

\section{HAL Id: hal-00294098 \\ https://hal.science/hal-00294098}

Submitted on 8 Jul 2008

HAL is a multi-disciplinary open access archive for the deposit and dissemination of scientific research documents, whether they are published or not. The documents may come from teaching and research institutions in France or abroad, or from public or private research centers.
L'archive ouverte pluridisciplinaire HAL, est destinée au dépôt et à la diffusion de documents scientifiques de niveau recherche, publiés ou non, émanant des établissements d'enseignement et de recherche français ou étrangers, des laboratoires publics ou privés. 


\title{
Fully three-dimensional direct numerical simulation of a plunging breaker
}

\author{
Simulation numérique directe tridimensionnelle du \\ déferlement plongeant
}

\author{
Pierre Lubin*, Stéphane Vincent*, Jean-Paul Caltagirone* and Stéphane \\ Abadie $^{+}$ \\ * Modélisation Avancée des Systèmes Thermiques et Écoulements Réels (MASTER) \\ ENSCPB - Université Bordeaux 1 \\ 16 Avenue Pey-Berland, 33607 PESSAC Cedex, France \\ + Laboratoire des Sciences Appliquées au Génie Civil (LaSAGeC) \\ ISA du BTP - Université de Pau et des Pays de l'Adour \\ 1 allée du Parc Montaury, 64600 Anglet, France \\ lubin@enscpb.fr stephane.abadie@univ-pau.fr \\ Tél. $0556846680 \quad$ Fax 0556846668
}

Short tittle Direct numerical simulation of a plunging breaker

Titre court Simulation numérique directe du déferlement plongeant

\begin{abstract}
The scope of this paper is to show the results obtained for simulating three-dimensional breaking waves by solving the Navier-Stokes equations in air and water. The interface tracking is achieved by a Lax-Wendroff TVD scheme (Total Variation Diminishing), which is able to handle interface reconnections. We first present the equations and the numerical methods used in this work. We then proceed to the study of a three-dimensional plunging breaking wave, using initial conditions corresponding to unstable periodic sinusoidal waves of large amplitudes. We compare the results obtained for two simulations, a longshore depth perturbation has been introduced in the solution of the flow equations in order to see the transition from a two-dimensional velocity field to a fully three-dimensional one after plunging. Breaking processes including overturning, splash-up and breaking induced vortex-like motion beneath the surface are presented and discussed.

\section{Résumé}

Une étude du déferlement tridimensionelle est présentée sur la base de résultats obtenus par simulation numérique directe des équations de Navier-Stokes diphasiques. Le suivi de l'interface est réalisé par l'utilisation du schéma TVD Lax-Wendroff (Total Variation Diminishing) qui permet de gérer les reconnexions de l'interface. Le déferlement est obtenu
\end{abstract}


à partir de l'initialisation dans un domaine semi-périodique d'une onde sinusoidale instable. Après présentation des équations et des méthodes numériques employées, une comparaison est effectuée entre deux simulations tridimensionelles et une discussion est menée quant à la nécessité d'utiliser une perturbation afin de destabiliser la symétrie du calcul. Les résultats obtenus sont alors commentés.

Key words fluid mechanics, Navier-Stokes, plunging breaker, numerical simulation

Mots clés mécanique des fluides, Navier-Stokes, déferlement plongeant, simulation numérique 


\section{French version}

Le déferlement des vagues est un phénomène fascinant qui joue un rôle de première importance dans les processus côtiers. A la fois source de courants très intenses et à l'origine de la majeur partie du transport sédimentaire, il est en outre responsable d'évènements critiques tels que l'érosion des plages ou la rupture d'ouvrages côtiers. Or, bien que largement étudié depuis une vingtaine d'années, le déferlement reste encore un problème très difficile à appréhender, aussi bien numériquement qu'expérimentalement.

Le problème considéré est l'écoulement de deux fluides incompressibles non miscibles. Le système d'équations régissant l'écoulement diphasique dans chacune des phases sont les équations de Navier-Stokes, accompagnées de la condition d'incompressibilité $(3-4)$.

Il est à noter que la viscosité et la densité sont constantes dans les deux phases de l'écoulement. Ce sont des fonctions du point que l'on détermine à partir de la position de l'interface entre les deux phases. Dans cette étude, les équations de Navier-Stokes sont résolues par la méthode du lagrangien augmenté.

Du point de vue de l'interface, le déferlement se caractérise par des déconnexions et reconnexions créant de nouvelles surfaces de toutes formes et de toutes tailles. Parmi les différentes méthodologies employées pour décrire l'évolution temporelle de l'interface eau / air, nous utilisons un schéma explicite TVD Lax-Wendroff. L'interface y est décrite par une fonction couleur $\mathrm{C}$ traduisant le coefficient de remplissage de l'eau dans chaque maille d'un maillage fixe. Cette représentation permet de traiter naturellement le problème de reconnexion de l'interface sur elle-même en comparaison à des méthodes à traceurs surfaciques. La valeur moyenne de la fonction $\mathrm{C}$ sur un volume représente alors la fraction volumique d'eau dans ce volume.

Le déferlement est étudié à partir de l'initialisation dans un domaine semi-périodique d'une onde sinusoidale instable. Une condition de symétrie est imposée sur les limites latérales et inférieure, tandis qu'une condition libre est laissée en limite supérieure du domaine de calcul. Les premières simulations tridimensionelles effectuées ont montré la nécessité de l'introduction d'une pertubation dans les équations de l'écoulement afin de déstabiliser le calcul. En effet, l'onde incidente étant initialisée à partir d'une solution bidimensionelle projetée sur l'axe transversal, nous avons constaté un comportement parfaitement symétrique de notre écoulement, celui-ci ne produisant spontanément aucune structure purement tridimensionelle. Une simulation, effectuée avec une perturbation numérique longitudinale, est alors analysée : on peut y voir un ensemble de structures comparables avec celles identifiées par d'autres auteurs. L'écoulement dans l'air attire en outre notre attention.

\section{Introduction}

The problem of wave breaking has been widely studied in the last two decades, as it has implications in coastal engineering, oceanography and naval hydrodynamics. As we can see in the works of Peregrine [1] and Christensen et al [2], great progresses have been done in the knowledge of the breaking problem. The three-dimensional and two-phase character of the problem and its turbulent behaviour make experimental and theoretical researches 
difficult to achieve. Since fully three-dimensional experimental techniques do not exist, three-dimensional flow structures are therefore complicated to obtain with certainty. The recent progresses in applied mathematics and computer architectures offer the possibility of developing a numerical model based on the three-dimensional Navier-Stokes equations to study the breaking phenomenon. The interest of this approach is to provide a complete descrition of free surface and velocity evolutions in the two phases, which must lead to the understanding of energy dissipation and turbulent flow structures.

Since breaker types are not only visually different in shape, but also in the kind of vortices they induce and in the way turbulence will affect sediment transport, it is important to investigate and to demonstrate the ability of the numerical tool to accurately describe the breaking phenomenon, considering the two media, air and water. This is indeed a great difference between previous published work and the study we present in this paper. Moreover, we tried to investigate the possibility to see fully three-dimensional structures by introducing a pertubation we can control in our flow equations, as the main goal of our future work is to study turbulence induced by breaking waves.

\section{Conservation equations and approximation method}

\subsection{Single fluid formulation of Navier-Stokes equations}

Let us consider the wave propagation problem as a two-phase flow involving a liquid phase (water) and a gaseous phase (air).

A general Navier-Stokes model for all fluids is designed by convolving the incompressible Navier-Stokes equations in each phase and the jump conditions across interface by an indicator function $C$ and by filtering the set of equations thanks to a volume integral operator. This function characterises one of the fluids, water for example, assuming the value 1 in the water zones and 0 in the others. The air parts are directly obtained as the complementary $1-C$ of the water parts. Assuming the interface between the fluids as the discontinuity of the indicator function, it is practically located by $C=0.5$ isoline. Several correlation terms are discarded in the single fluid model assuming the sliding between the phases to be negligible and no phase change occurs. The corresponding free surface flow admits a continuous velocity field through the free surface and is locally isovolume.

Let $\mathbf{u}$ be the velocity field, $\mathbf{g}$ the gravity vector, $\mathrm{p}$ the pressure, $\sigma$ the surface tension, $\kappa$ the curvature, $\mu$ the viscosity and $\rho$ the density. In a uniform Cartesian coordinate system $(\mathrm{x}, \mathrm{z})$, associated with a bounded domain $\Omega$, the one-fluid model can be expressed as follows

$$
\begin{gathered}
\mu=\mu_{1}, \rho=\rho_{1} \text { if } C>0.5 \\
\mu=\mu_{0}, \rho=\rho_{0} \text { if } C<0.5 \\
\nabla \cdot \mathbf{u}=0 \\
\rho\left(\frac{\partial \mathbf{u}}{\partial t}+(\mathbf{u} \cdot \nabla) \mathbf{u}\right)=\rho \mathbf{g}-\nabla p+\nabla \cdot\left[\mu\left(\nabla \mathbf{u}+\nabla^{T} \mathbf{u}\right)\right]+\sigma \kappa \delta_{i} \mathbf{n}_{i} \\
\frac{\partial C}{\partial t}+\mathbf{u} \cdot \nabla C=0
\end{gathered}
$$


where $\delta_{i}$ is a Dirac function indicating the interface, $\mathbf{n}_{i}$ is the unit normal to the interface and $\rho_{0}, \rho_{1}, \mu_{0}$ and $\mu_{1}$ are the respective densities and viscosities in each phase. Equations (1) and (2) corresponds to a discontinuous estimate of the physical characteristics. We proved this method to be less diffusive than the usual linear formula used in the literature.

The evolutions of the free surface and the physical characteristics of the fluids are simultaneously represented by means of equations $(1-5)$. The free surface flow is analysed in terms of an equivalent single fluid whose variable properties $\rho$ and $\mu$ are related to $\rho_{0}$, $\rho_{1}, \mu_{0}$ and $\mu_{1}$ of the real two phases by the colour function $\mathrm{C}$.

\section{$2.2 \quad$ Numerical methods}

\subsubsection{Interface capturing method and surface tension discretisation}

All interface capturing methods are dedicated to solving the advection equation of a discontinuous indicator function $\mathrm{C}$ through the reformulation of the transport equation with a smooth function. We choose to implement the explicit Lax-Wendroff TVD (LWT) time-stepping scheme dedicated to volume fraction advection, widely explained in Vincent and Caltagirone ([3] and [4]). This approach allows to solve precisely free-surface flows inducing strong tearing and stretching of interface which will occur in breaking water waves.

Due to the volumic representation of interface, the geometrical properties of interface $\kappa, \delta_{i}$ and $\mathbf{n}_{i}$ are not directly accessible. To avoid calculating explicitly these free surface properties, they are modeled as a function of the volume fraction. The Continuum Surface Force (CSF) method of Brackbill et al [5] is used to model the surface tension acting in the Navier-Stokes equations (4).

\subsubsection{Navier-Stokes solver}

A Finite-Volume method on a staggered mesh is carried out to discretise the Navier-Stokes equations and an augmented Lagrangian technique is investigated to solve the coupling between pressure and velocity in the equations of motion $(3-4)$.

The discretisation of these equations is achieved through a second-order Euler scheme, or GEAR scheme, on the time derivatives while a second order Hybrid Centered-Upwind scheme is devoted to the non-linear convective terms and a second order centered scheme is chosen for the approximation of the viscous and the augmented Lagrangian terms. The linear system resulting from the previous implicit discretization is solved with an iterative BiCGSTAB (Bi-Conjugate Gradient Stabilised) algorithm, preconditioned under a Modified and Incomplete LU (MILU) algorithm. All the references concerning the numerical methods can be found in [3] and [4]. 


\section{Three-dimensional simulation of plunging wave break- ers over a flat bottom}

All our calculations are made with the densities and the viscosities of air and water $\left(\rho_{a}=\right.$ $1.1768 \mathrm{~kg} \cdot \mathrm{m}^{-3}$ and $\rho_{w}=1000 \mathrm{~kg} \cdot \mathrm{m}^{-3}, \mu_{a}=1.85^{-5} \mathrm{~kg} \cdot \mathrm{m}^{-1} \cdot \mathrm{s}^{-1}$ and $\mu_{w}=1^{-3} \mathrm{~kg} \cdot \mathrm{m}^{-1} \cdot \mathrm{s}^{-1}$ ), and $\sigma=7.5 \cdot 10^{-2} N . m^{-1}$.

The numerical method has been validated on different cases, as shown by Abadie et al [6] and Lubin et al [7], such as dam-break flows, propagations of non linear steady water waves or solitary waves over horizontal beds in periodic domains.

\subsection{Definition sketch}

As already shown in Vinje and Brevig [8], Abadie et al [6], Chen et al [9], Abadie [10], Lubin et al [7], we use initial conditions corresponding to unstable periodic sinusoidal waves of large amplitude, the initial quantities being calculated from the linear theory. Such a wave cannot remain steady as the initial velocity field in water is not stable with the initial wave profile. As it is not a steadily travelling wave and it is steeper than an irrotational steady wave, these initial conditions lead to breaking waves. The overturning motion is therefore controlled by the initial steepness and the dispersion parameter, which makes our approach interesting as we are then able to study any breaker type by only varying these two parameters introduced latter on. We can study accurately the breaking phenomenon in a smaller numerical domain, as it is periodical in the flow direction, compared to simulations involving a shoaling wave breaking over a sloping beach.

The calculation domain is periodic in the flow direction (one wavelength long), with a symmetry boundary condition in the lower and lateral limits, and a free boundary condition in the upper limit. The reference variables of the initial incident wave are the celerity $c$, the period $T$ and the wavelength $L$, the densities and viscosities of air and water media. The depth is defined by $d$ and the waveheight is referred as $H$. The flow motion is driven by the Reynolds number, $R e=\frac{\rho c L}{\mu_{w}}$, the Froude number, $F r=\frac{c}{\sqrt{g L}}$, the density ratio, $\frac{\rho_{a}}{\rho_{w}}$, the viscosity ratio, $\frac{\mu_{a}}{\mu_{w}}$, the initial steepness, $\frac{H}{L}$, and the dispersion parameter, $\frac{d}{L}$. The last two dimensionless numbers are respectively representative of the non linearity degree of the wave and the influence of the bottom on oscillatory movement. Two ratios are constant in our work, $\frac{\mu_{a}}{\mu_{w}}=1.8510^{-2}$ and $\frac{\rho_{a}}{\rho_{w}}=1.176810^{-3}$, as we are only interested in simulating breaking waves in real conditions.

Three-dimensional simulations are leaded with the two-dimensional initial $(\mathrm{x}, \mathrm{z})$ solution spread in the y-direction. As a periodic condition is imposed in the direction of wave propagation, the wave moves out of the domain on the right side to re-enter on the left side. 


\subsection{Free surface and vortex analysis}

Once we validated the breaking process described briefly in terms of wave overturning and splash-up occurrence [7], which is in accordance with the general observations found in the literature, we then proceed to the study of another plunging breaking wave by the same method. We choose to simulate and present a plunging breaker with $\frac{H}{L}=0.13$ and $\frac{d}{L}=0.17$, as shown here after (Fig. 1a). We present the initial condition with $C \geq 0.5$, without the velocity field vectors, in order to see the water medium. The interface is chosen to be at $C=0.5$. We recall that the full Navier-Stokes equations are solved in both air and water.

Two simulations are carried out with the same parameters, but the first one was done without pertubation and the second one with a long-shore depth perturbation, so we could compare the different structures we get. We use a regular cartesian grid of $250 \times 100 \mathrm{x}$ 25 points. The time step is approximately $0,1 \mathrm{~ms}$.

During our simulations, we observed the velocity field did not develop spontaneously any three-dimensional flow structures and we did not see any difference with two-dimensional simulations proceeded with the same parameters. As a matter of fact, it seemed obvious to conclude that we would not be able to study turbulence induced by breaking waves if no pertubation is introduced one way or another in this already unsteady wave. It seems natural to consider any physical parameter we can control in our problem, a pertubation coming from a numerical scheme would not be acceptable as it would be hard to evaluate and so to rely on. That is why we naturally consider a change of depth as we initialise our flow equations: the free surface is kept uniform in shape and the velocity field (6) has the information of a variation of depth from the pertubed bottom $d^{*}=d+\epsilon, \epsilon$ being a small quantity chosen to vary linearly along the y-axis. This numercial perturbation leads to an unsymmetrical flow with respect to the long-shore axis.

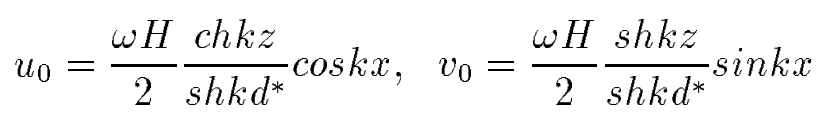

with $\omega$ being the angular frequency and $k$ the wave number.

We checked there appeared no difference before the jet impact between the two simulations, the distance of the impact being the same. The perturbation does not influence the overturning motion. Before plunging, the flow remains two-dimensional. The splash-up generated rises as high as the initial waveheight. A second jet is then generated and this process is observed to repeat, each successive splash-up being weaker than the preceeding one. The perturbation starts to grow when the second jet is falling down. We can then comment fully three-dimensional big-scale structures that appears as, for exemple, the two counter-rotative vortices showed in different vertical slices (Fig. 2), the interface being located with $C=0.5$.

When the first jet is formed and falls down, a large amount of air is entrained in the water (Fig. 1b). The air resists, as it is envelopped by the tongue of water, and induces a great shear rate at the free-surface. A first vortex is then formed. This topologically 
generated vorticity is one of the greatest source of turbulence. The flow becomes very turbulent and violent in both media. We can then see that we got a high splash-up (Fig. 1c) generating two counter-rotative vortices (Fig. 2 and 3), as observed by Bonmarin [11], and three co-rotative vortices (Fig. 1e and 3), as observed by Miller [12] or Sakai et al [13]. We could see some gaz pockets rising to the free surface and the air exploding as a spout (Fig. 1d and Fig. 1e). We show the velocity field in both media at the instant $t=0.40 \mathrm{~s}$ (Fig. 2). We can see the dipole formed by the two counter-rotative vortices separating as one of them is stretching and rising to the surface (Fig. 2a and $3 \mathrm{~b}$ ), due to the buoyancy effect. We can notice the topologically generated vorticity, the flow between the two counter-rotative vortices being due to the impact of the projected tongue of water. The air entraped in the biggest vortex is rising on one side of the domain as it is still sinking and rotating at the other side. The tube is then twisting along the y-axis, whereas in the non perturbed case the tube stays straight as it is dragged to the bottom. We can see on the pictures shown in the appendix (Fig. 2) that we can see through the tube of air entraped in the volume.

The next step will be to study the effect of the size of our computational domain in the $y$-direction with a periodic boundary condition. A good care will be taken to ensure that enough room is left to let any three-dimensional structures develop without being constrained by an artificial box effect. We will also vary the long-shore pertubation in order to investigate its influence on the flow. The flow induced in the air will also be investigated in details.

\section{Concluding remarks}

As the purpose of our future work is to improve the understanding of turbulence induced by breaking waves, we have obtained promising results, assuming that three-dimensional simulations without a turbulence model of any kind would give a reasonable indication of the processes which happen when waves break, considering that the initial flow is irrotational. We used an artificial way of making the wave break as it is not a real bathymetric variation that leads to the overturning motion, but an unsteady initial condition. The next step will be to describe turbulence induced by solitary waves breaking on beaches by large eddy simulation, as Watanabe et al [14] and Christensen and al [15].

\section{Acknowledgements}

The authors would like to aknowledge the financial and scientific support of the french INSU - CNRS (Institut National des Sciences de l'Univers - Centre National de la Recherche Scientifique) program "Programme Atmosphère-Océan Multi-échelle" (PATOM) and the IDRIS-CNRS (Institut du Développement et des Ressources en Informatique Scientifique) and CINES (Centre Informatique National de l'Enseignement Supérieur) for their material support. 


\section{Appendix}

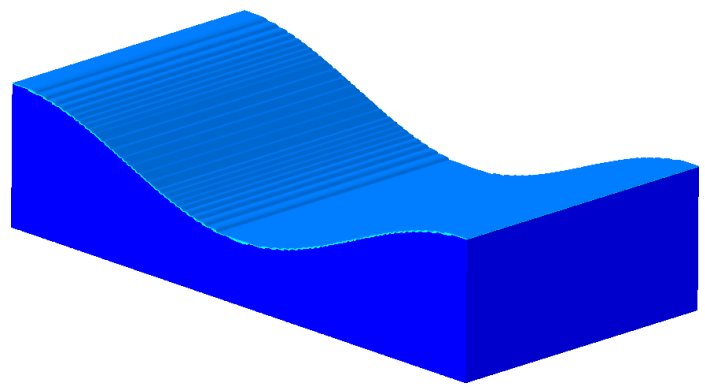

a. $\quad \mathrm{t}=0 \mathrm{~s}$

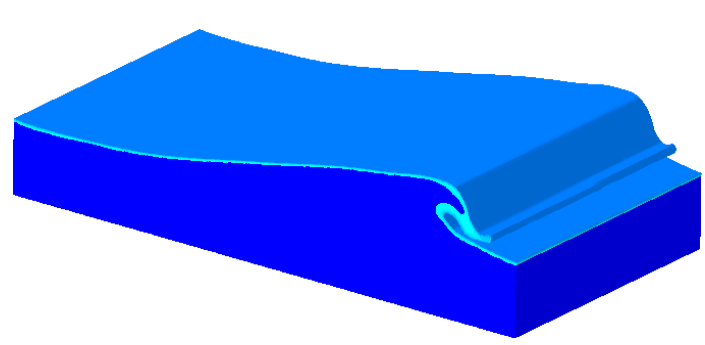

b. $\quad t=0.18 \mathrm{~s}$

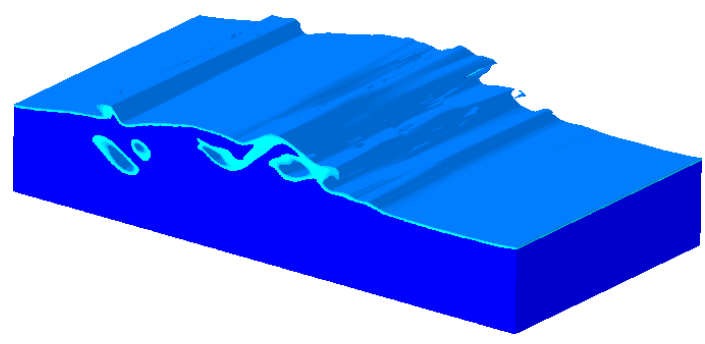

d. $\mathrm{t}=0.35 \mathrm{~s}$

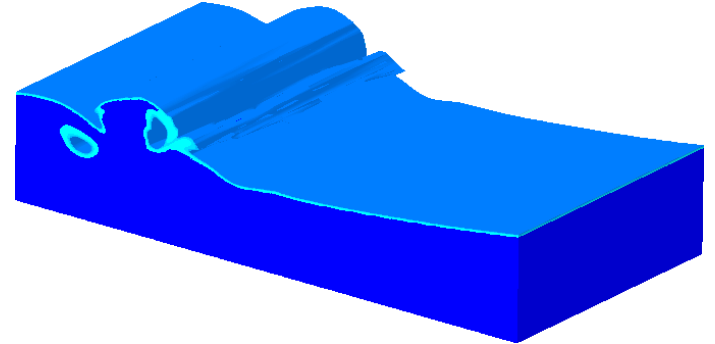

c. $\mathrm{t}=0.28 \mathrm{~s}$

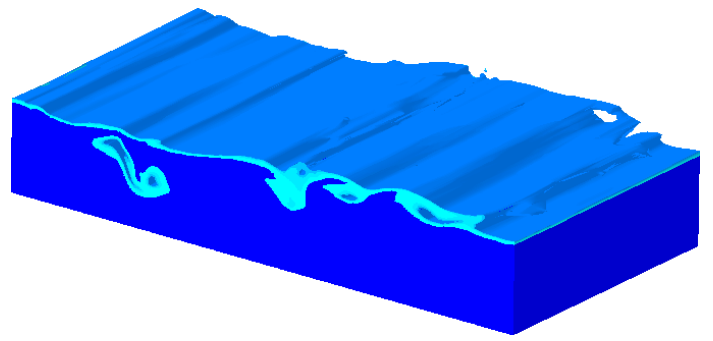

e. $\mathrm{t}=0.42 \mathrm{~s}$

Figure 1: Three-dimensional simulations. $\frac{H}{L}=0.13, \frac{d}{L}=0.17, C \geq 0.5$.

Simulations tridimensionelles. $\frac{H}{L}=0.13, \frac{d}{L}=0.17, C \geq 0.5$. 


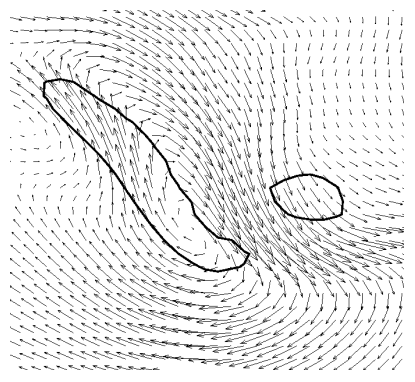

a. Frontside

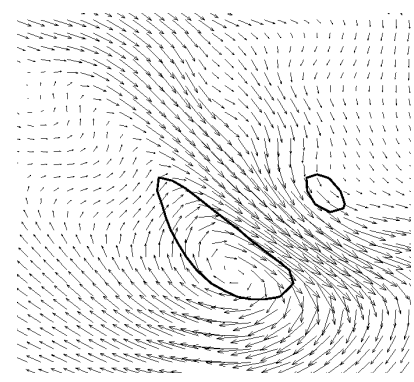

b. Middle

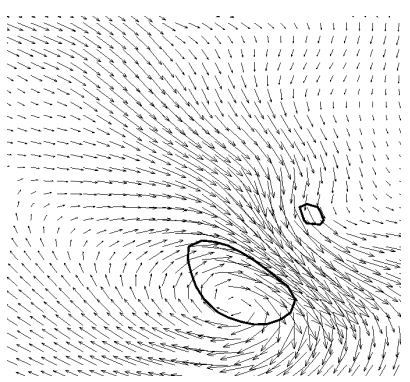

c. Backside

Figure 2: Anisotropy of the counter-rotative vortices and the velocity field along the y-axis - zoom, vertical slices.

Vortex contra-rotatifs et champs de vitesse - gros plan, coupes verticales.

$$
C=0.5, t=0.40 s \text {. }
$$

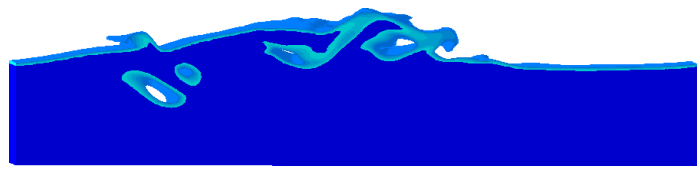

a. $\mathrm{t}=0.35 \mathrm{~s}$

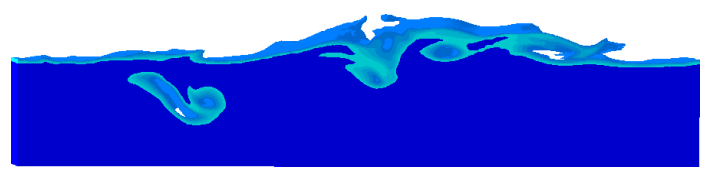

b. $\mathrm{t}=0.41 \mathrm{~s}$

Figure 3: Counter-rotative and co-rotative vortices - zoom, frontside view of the domain. Vortex contra et co-rotatifs - gros plan, vue de côté. 


\section{References}

[1] D. H. Peregrine, Breaking waves on beaches, Ann. Rev. Fluid Mech., 15:149-178, 1983.

[2] E. D. Christensen, D. J. Walstra and N. Emarat, Vertical variation of the flow across the surf zone, Coastal Eng., 45:169-198, 2002.

[3] S. Vincent and J.P. Caltagirone, Efficient solving method for unsteady incompressible interfacial flow problems, Int. J. Numer. Meth. Fluids, 30:795-811, 1999.

[4] S. Vincent and J.P. Caltagirone, A One Cell Local Multigrid method for solving unsteady incompressible multi-phase flows, J. Comput. Phys., 163:172-215, 2000.

[5] J. U. Brackbill, B. D. Kothe and C. Zemach, A continuum method for modeling surface tension, J. Comput. Phys., 100:335-354, 1992.

[6] S. Abadie, J.-P. Caltagirone and P. Watremez, Mécanisme de génération du jet secondaire ascendant dans un déferlement plongeant, C. R. Acad. Sci. Paris, Série II $b, 326: 553-559,1998$.

[7] P. Lubin, S. Vincent, J.-P. Caltagirone and S. Abadie, Fully three-dimensional direct numerical simulation of plunging breaking waves, Coastal Engineering 2003, 6th International Conference on Computer Modelling and Experimental Measurements of Seas and Coastal Regions, Cadiz, Spain, (accepted for publication) 2003.

[8] T. Vinje and P. Brevig, Numerical simulation of breaking waves, J. Adv. Water Resour., 4:77-82, 1981.

[9] G. Chen, C. Kharif, S. Zaleski and J. Li, Two-dimensional Navier-Stokes simulation of breaking waves, Phys. Fluid, 11:121-133, 1999.

[10] S. Abadie, Numerical modelling of the flow generated by plunging breakers, Proceedings Coastal Dynamics, Lund, Sweden, 202-211, 2001.

[11] P. Bonmarin, Geometric propertries or deep-water breaking waves, J. Fluid Mech., 209:405-433, 1989.

[12] R. L. Miller, Role of vortices in surf zone prediction: sedimentation and wave forces, Soc. Econ. Paleontol. Mineral. Spec. Publ., Ed. R. A. Davis, R. L. Ethington, 24:92-114, 1976.

[13] T. Sakai, T. Mizutani, H. Tanaka and Y. Tada, Vortex formation in plunging breaker, Proc. of the 20th ICCE, 711-723, 1986.

[14] Y. Watanabe and H. Saeki, Thee-dimensional large eddy simulation of breaking waves, Coastal Engineering Journal in Japan, 3 and 4:281-301, 1999.

[15] E. D. Christensen and R. Deigaard, Large eddy simulation of breaking waves, Coastal Eng., 42:53-86, 2001. 